\title{
Foreword 2
}

\section{Michael Beer ${ }^{1}$}

A discouraging seventy percent of corporate transformations don't live up to expectations. Many managers I have spoken to think their own company simply cannot change, much as it needs to. They've seen previous efforts fail and they have a pretty good idea why they failed. Since the underlying reasons for failure haven't changed, why should the results? But in a business environment demanding rapid adaptation to everything from ever changing competitive challenges to COVID to robots to Black Lives Matter, so much failure to transform is unacceptable. Indeed, this is reflected in the decreasing tenure of CEOs and the public's decreasing trust in institutions. A better way has to be found and this book makes an important contribution to our knowledge about how that can be done through collaborative inquiry and action.

My first consulting engagement was at a factory whose leadership wanted to become a "Theory Y" organization - Douglas McGregor's designation for participative management (McGregor, 1960). Naturally, I began with a workshop to teach them the ideas underlying Theory $\mathrm{Y}$ and participative management. Senior management told me this was interesting but not helpful. I then pivoted to working collaboratively with managers on solving their immediate problems. That led to new insights, confirmed by subsequent experience and field research, about the power of collaborative inquiry and conversation to develop better solutions. Better, in part, because the process of developing the solution simultaneously develops what's usually missing - commitment to that solution.

As the authors of this book show, abstract ideas generated by "normal" positivistic research do not help managers because they are uncontextualized; they do not reflect the specific and grounded circumstances of a particular organization as understood by its members. Moreover, knowledge-first approaches to change assume that re-education will transform attitudes and ultimately behavior. This assumption misses the point. Changes in behavior occur only when people are involved in identifying problems, diagnosing the causes, and then redesigning their 
organization and their own behavior and practices. Organizations are systems in which causality is both multifaceted and circular. That is, a multitude of hard (technical) and soft (social and emotional) facets are always at work and are always affecting each other. Thus, for valid solutions and commitment to be developed, those within the system must be involved, especially those at the top who will have to lead and manage differently.

In a study of corporate transformation, my colleagues and I found that change programs launched from the top - usually consisting of education and training but sometimes also involving changes in structure, policies, and practices - failed to change much (Beer et al., 1990). Pressure for short-term results and the leaders' natural desire to avoid the topic of their own ineffectiveness blinded them to the need for a slower - potentially more painful - collaborative process of discovery, learning and change. Meanwhile, the lower levels, who, I have found, know a lot about why the organization is not working, are unable to speak truth to power about barriers to effectiveness, trust and commitment. As Chris Argyris noted, hierarchical organizations - that's all organizations - are built for cover-up.

No abstract journal article or education program can overcome these realities. An experience I had while teaching in the Harvard Business School's Advanced Management Program confirms this. Toward the end of the program participants - all senior executives in their company - asked to speak with me. They thought my ideas about organizational effectiveness and change were important and relevant to their own organization, but they were sure that their CEO and their senior team did not and would not understand the problems they themselves now recognized. They saw their organization's system of organizing, managing and leading stuck in neutral and even though they now felt they knew what needed to be done, they didn't see any way to convince their top management to act. As I myself have seen over and over, very many executives and managers feel trapped this way - and they might be surprised at how often their CEOs and senior teams feel similarly trapped. As the authors of this book argue, the only way out of this trap is a collaborative inquiry between those at the top and those below whose daily frustrations with the organization's ineffectiveness can provide those at the top with important insights into the problems that must be confronted and solved. Collaboration requires a partnership, open and honest conversations between the top team and key lower-level managers below them who know first hand and in detail what is working and not working. This 
honest conversation in turn requires a container - that is, a structure and process - that keeps it safe and productive so that it will lead to a different understanding of the system of organizing, managing and leading.

My own experience and research confirm that honest conversations consistently identify the organization's people as a strength, but also identify silent (that is, not openly discussable) barriers that frustrate people's efforts to execute senior management's strategic and values directions. These barriers are lack of clarity about strategy and values, poor coordination and collaboration attributable to a poorly designed organization by an ineffective leader and leadership team, inadequate leadership development and, consequently, a paucity of effective down-the-line leaders, and poor vertical communication and collaboration between the top and lower levels, particularly the inability of lower levels to speak truth to power. That prevents the requisite open and honest collaborative inquiry required for productive change. These barriers are difficult to talk about and therefore require an organization development consultant who facilitates the collaborative inquiry and offers managers valid heuristic frameworks with which to redesign their system of organizing, managing and leading. Nevertheless, it is the managers, not the consultant, who must decide and thereby arrive at the commitment needed to transform the system. The most important lesson here for managers is the collaborative inquiry process itself. The process must be safe for those involved, and have no negative consequences for the people involved. If the collaborative inquiry is successful, the organization may choose to use it repeatedly as its method of change and its engine of continuous learning, improvement and development. That is what it will take to survive and prosper.

\section{NOTE}

1. Harvard Business School and Center for Higher Ambition Leadership. 